\title{
Cell Cycle Arrest and Apoptosis Induction by a New 2,4- Dinitrobenzenesulfonamide Derivative In Acute Leukemia Cells
}

\author{
Patricia Alves de Almeida ${ }^{1,2}$, Luiz Felipe Schmitz de Souza ${ }^{3}$, Mariana Franzoni Maioral ${ }^{1,2}$, Bruna Fischer Duarte ${ }^{1,2}$, Laura \\ Otto Walter ${ }^{1,2}$, Íris Mattos Santos Pirath ${ }^{1,2}$, Douglas Bauer Speer ${ }^{1,2}$, Larissa Sens ${ }^{3}$, Tiago Tizziani ${ }^{3}$, Aldo Sena de Oliveira ${ }^{4}$, \\ Ricardo José Nunes ${ }^{3}$, Maria Cláudia Santos-Silva ${ }^{1,2}$.
}

\begin{abstract}
${ }^{1}$ Laboratory of Experimental Oncology and Hemopathies, Department of Clinical Analysis, Federal University of Santa Catarina, Florianópolis, Brazil. ${ }^{2}$ Postgraduate Program in Pharmacy (PGFAR), Federal University of Santa Catarina, Florianópolis, Brazil. ${ }^{3}$ Laboratory of Structure and Activity, Department of Chemistry, Federal University of Santa Catarina, Florianópolis, Brazil. Department of Exact Sciences and Education, Federal University of Santa Catarina, Blumenau, Brazil.
\end{abstract}

\begin{abstract}
Corresponding Author. Maria Cláudia Santos-Silva, Experimental Oncology and Hemopathies Laboratory, Clinical Analysis Department, Federal University of Santa Catarina; 88040-900, Florianópolis, SC, Brazil; TEL: (+55) 48 37218146; email: maria.claudia.silva@ufsc.br
\end{abstract}

Received, September 9, 2020; Revised, December 16, 2020; Accepted, December 27, 2020; Published, January 8, 2021

\begin{abstract}
Background: Current therapies for acute leukemias (ALs) are associated with severe adverse reactions and high relapse rates, which makes the search for new antileukemic agents a necessity. Therefore, the aim of this study was to evaluate the effects of a new sulfonamide, S1, in AL cells K562 and Jurkat. Methods: The cytotoxic activity of S1 was assessed using MTT method. The involvement of apoptosis in the mechanism of cell death was assessed by flow cytometry and fluorescence microscopy. Results: Our results demonstrated that S1 induced morphological changes suggestive of apoptosis in both K562 and Jurkat cells. Additionally, S1 was not cytotoxic to normal erythrocytes and mononuclear cells and had a highly selective cytotoxicity for AL lineages. The mechanisms of cell death induced by S1 in K562 cells involves cell cycle arrest at G2/M phase and the activation of both extrinsic and intrinsic apoptosis, with an increased FasR and AIF expression and the loss of mitochondrial potential. As for Jurkat, we observed cell cycle blockade at G0/G1 phase, phosphatidylserine exposure and the involvement of intrinsic apoptosis only, with mitochondrial potential loss and a reduced expression of Survivin. Although sulfonamide S1 did not altered Bcl-2 and Bax expression in AL cell lines, it was able to activate caspase-3 in K562 cells. Conclusion: Our results suggest that sulfonamide S1 may be a promising candidate for the development of new drugs for the treatment of ALs.
\end{abstract}

\section{INTRODUCTION}

Acute leukemias (ALs) are heterogeneous hematological malignant diseases that involve uncontrolled cell proliferation, abnormalities in cell maturation and differentiation, and the ability to self-renewal during hematopoiesis $(1,2,3)$. While in chronic leukemias there is an exacerbated production of mature non-functional cells, in ALs the maturation capacity is lost, leading to the accumulation of immature cells (blasts) in the bone marrow (BM) and/or peripheral blood (PB) (4). Treatment for ALs is based mainly on chemotherapy with combined cytotoxic drugs that aim to induce regulated cell death to the leukemic blasts and then restore normal hematopoiesis $(5,6)$. However, currently available chemotherapeutic drugs are not selective for neoplastic cells, which results in severe adverse effects that compromise the patients' life quality. In addition, the high relapse rates, and the frequent development of drug resistance during $\mathrm{AL}$ treatment decrease the therapeutic options and aggravate the patients' clinical condition $(4,5)$.

It is known that the inhibition of apoptosis causes an imbalance between cell proliferation and cell death, which is highly associated with the malignant phenotype (7). Consequently, the activation of signaling pathways that trigger apoptosis is one of the most successful mechanisms of chemotherapeutic drugs, as it can eliminate tumor cells in a regulated manner (5). In the past few decades, no significant progress has been made regarding the therapy against ALs. Taking this together with the well-known obstacles faced in currently available treatments, such as unfavorable prognosis, resistance to therapy, relapses and low selectivity, the search for more effective and specific drugs is mandatory $(8,9)$. As mentioned before, compounds that induce regulated cell death through apoptosis or cell cycle arrest are promising strategies in the search for new antileukemic 
agents. In this regard, sulfonamides are drugs with several derivatives that have different biological activities, such as antimalarial (10), antimicrobial (11) and antitumor effect $(11,12)$. In addition to the sulfonyl group bonded to an amino group (or sulfonamidic group) $\left(\mathrm{SO}_{2} \mathrm{NH}_{2}\right)$, the main structure of sulfonamides has an amino group $\left(\mathrm{NH}_{2}\right)$ at the para position of a benzene ring $(13,14,15,16,17)$. Previous studies have demonstrated the antineoplastic activity of sulfonamides or their derivatives on leukemia cell lines $(18,19,20,21)$. However, many of these studies do not show the specific cytotoxicity mechanisms exerted by the compounds analyzed. Thus, in the present study, we investigated the cytotoxic effects and the main apoptotic mechanisms of a new sulfonamide derived from 2,4 dinitrobenzenesulfonyl in $\mathrm{AL}$ cells K562 and Jurkat.

\section{MATERIALS AND METHODS}

\section{Sulfonamide synthesis and characterization}

The compound N,N'-(ethane-1,2-diyl)bis(2,4dinitrobenzenesulfonamide) (S1) was previously selected from a series of sulfonamides screened for their cytotoxic potential in K562 cells (see supplementary Figure 1). S1 was prepared with 2 mmol of 2,4-dinitrobenzene-1-sulfonyl chloride and $1 \mathrm{mmol}$ of ethane-1,2-diamine as previously described (22) (Figure 1). Briefly, reagents were placed under magnetic stirring for 24 hours at room temperature with $10 \mathrm{~mL}$ of dichloromethane. Then, $10 \mathrm{~mL}$ of methanol was added, and the reactions were accompanied by thin layer chromatography.
The precipitates were filtered and dried. Sulfonamide $\mathrm{S} 1$ was characterized by ${ }^{1} \mathrm{H}$ and ${ }^{13} \mathrm{C}$ nuclear magnetic resonance (NMR) spectroscopy and melting points (MP). ${ }^{1} \mathrm{H}$ and ${ }^{13} \mathrm{C}$ NMR spectra were obtained using a Bruker Avance DRX 400 (Billerica, USA), (operating at $400 \mathrm{MHz}$ for ${ }^{1} \mathrm{H}$ and $100 \mathrm{MHz}$ for ${ }^{13} \mathrm{C}$ ), with tetramethylsilane as internal standard. MP were determined with a Microquimica MGAPF-301 (Campinas, Brazil) apparatus. The compound was confirmed by mass spectrometry, using the high-resolution mass spectra (HRMS) and recorded on a micrOTOF-QII (Bruker, Billerica, USA) mass spectrometer, equipped with an automatic syringe pump (KD Scientific, Holliston, USA) for sample injection (constant flow of $3 \mu \mathrm{L} \mathrm{min}^{-1}$ ), by positive mode of atmospheric pressure chemical ionization (APCIMS) technique $\left(4.5 \mathrm{kV}\right.$ and $\left.200{ }^{\circ} \mathrm{C}\right)$ using acetonitrile as solvent. The instrument was calibrated in the range $\mathrm{m} / \mathrm{z} \mathrm{50-3000} \mathrm{using} \mathrm{an}$ internal calibration standard (low concentration tuning mix solution), supplied by Agilent Technologies (Santa Clara, USA). Data was processed via Bruker Data Analysis software (version 4.0). When the calculated and experimental masses were compared, the error was as expected $(<2 \mathrm{ppm})$. Before the experimental procedures, sulfonamide $\mathrm{S} 1$ was diluted in dimethylsulfoxide (DMSO) to prepare the stock solution $(10 \mathrm{mM})$ and stored at $4{ }^{\circ} \mathrm{C}$. All reagents were obtained commercially (Sigma-Aldrich, São Paulo, Brazil), and all solvents used were analytical grade, without additional purification.
2<smiles>O=[N+]([O-])c1ccc(S(=O)(=O)Cl)c([N+](=O)[O-])c1</smiles>

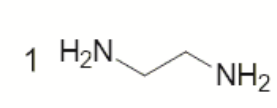

$\underset{\text { r.t. } 24 \mathrm{~h}}{\stackrel{\mathrm{CH}_{2} \mathrm{Cl}_{2}}{\longrightarrow}}$

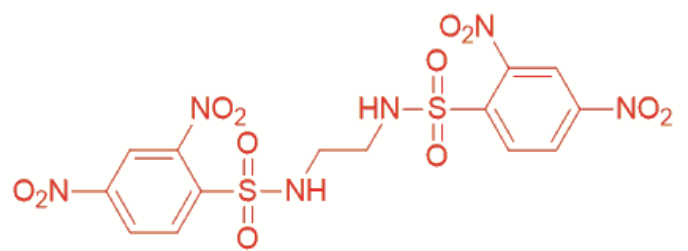

Figure 1. Synthesis and chemical structure of sulfonamide S1

\section{In silico evaluation}

ADMETSAR 2.0 and OSIRIS platforms were used to predict the physicochemical and biological profiles of sulfonamide $\mathrm{S} 1(23,24)$.

\section{Cell culture}

Two human AL cell lines were included in this study: K562 (chronic myeloid leukemia in blast phase, used as a model of acute myeloid leukemia, AML) and Jurkat (T-cell acute lymphoblastic leukemia, ALL). Cells were maintained in culture flasks under $5 \% \mathrm{CO}_{2}$ humidified atmosphere, $37^{\circ} \mathrm{C}$ and cultured in Roswell Park Memorial Institute (RPMI) 1640 medium, $\mathrm{pH}$ 7.2, supplemented with $10 \%$ inactivated fetal bovine serum, $100 \mathrm{U} / \mathrm{ml}$ penicillin, $100 \mu \mathrm{g} / \mathrm{ml}$ streptomycin and $10 \mathrm{mM}$ HEPES (Gibco, São Paulo, Brazil). The viable cells were counted by the Trypan blue method (25) and only samples with at least $90 \%$ of cell viability were used in the experiments. 


\section{Cell viability assays}

K562 and Jurkat cells were seeded, respectively, at $1 \times 10^{5}$ and $2 \times 10^{5}$ cells/well (12 hours), $5 \times 10^{4}$ and $1 \times 10^{5}$ cells/well (24 hours), $2.5 \times 10^{4}$ and $5 \times$ $10^{4}$ cells/well (48 hours). Then, cells were incubated with 1 to $100 \mu \mathrm{M}$ of sulfonamide S1 for 12,24 and 48 hours. Cell viability was assessed by the 3-(4,5-dimethyl-2-thiazolyl)-2,5-diphenyl-2H tetrazolium (MTT) colorimetric assay as previously described (26) and the optical densities (OD) were detected at $540 \mathrm{~nm}$ in a Microwell Systems Spectrophotometer (Organon Teknika, Turnhout, Belgium). OD of the control groups (untreated cells) were considered as $100 \%$ of cell viability. The $50 \%$ inhibitory concentrations (IC50) were calculated using GraphPad Prism 5 software.

\section{PB assays}

PB samples from four nonsmoker healthy volunteers took part of this study (University Human Research Ethics Committee - CEPSH $\left.\mathrm{n}^{\circ} 72.838 .107 / 2018\right)$. The samples were collected, and mononuclear cells (MC) were isolated by Ficoll-Hypaque (density $1.077 \mathrm{~g} / \mathrm{m}^{3}$, SigmaAldrich, São Paulo, Brazil) and seeded at 7,5 x $10^{5}$ cells/well for 24 hours with 1-10 $\mu \mathrm{M}$ of S1. Cell viability was assessed by MTT and the IC50 was calculated as previously described. The ratio between the IC50 obtained in peripheral blood mononuclear cells (PBMC) and the IC50 obtained in AL cells was used to determine the selectivity index (SI) of sulfonamide S1 according to the following equation: SI = IC50 $\mathrm{PBMC} / \mathrm{IC} 50$ leukemia cells $(27,28)$. A high selectivity was considered as SI > 3 (29,30). The hemolytic activity of sulfonamide S1 was evaluated in erythrocytes. Briefly, PB samples were collected, washed twice with saline $(0.9 \% \mathrm{NaCl})$ and the erythrocytes were resuspended to obtain a stock dispersion. Thereafter, saline (negative control, $100 \%$ membrane integrity), water (positive control, $0 \%$ membrane integrity) or saline containing 5 to $100 \mu \mathrm{M}$ of sulfonamide S1 were added to the erythrocyte dispersion. After incubation at $37{ }^{\circ} \mathrm{C}$, the samples were centrifuged, and the supernatants were read at $540 \mathrm{~nm}$. The hemolysis rate was calculated by the following equation: Hemolysis rate $(\%)=(\mathrm{Dt}-\mathrm{Dnc}) /(\mathrm{Dpc}-\mathrm{Dnc}) \times 100$, where: $\mathrm{Dt}$, OD of the test sample; Dnc, OD of the negative control; Dpc, OD of the positive control.

\section{Cell cycle evaluation}

K562 and Jurkat cells $\left(1 \times 10^{6}\right.$ cells/well $)$ were incubated for 24 hours at the 24-hour IC50 $\left(\mathrm{IC} 50_{24 \mathrm{~h}}\right)$ of sulfonamide S1. Cells were then fixed with $70 \%$ ethanol, washed with $2 \%$ bovine serum albumin solution, and incubated with propidium iodide (PI) (PI/RNAse solution kit) (SigmaAldrich, Saint Louis, USA) according to the manufacturer's instructions. Cells (20,000 events) were acquired in BD FACSCanto ${ }^{\mathrm{TM}}$ II flow cytometer (Becton Dickinson Immunocytometry Systems) and data were analyzed by Infinicyt software version 1.7 (Cytognos®). The negative control was prepared with untreated cells, the doublets were withdrawn using FSC High and FSC Area.

\section{Apoptosis assays}

Apoptotic cells were evaluated by the observation of morphological alterations with acridine orange (AO) and ethidium bromide (EB) (31) and by the phosphatidylserine exposure with the Annexin VFITC Apoptosis Detection kit (Immunostep, Salamanca, Spain). K562 and Jurkat cells (1 x $10^{6}$ cells/well) were incubated for 12 hours with $\mathrm{S} 1$ at $\mathrm{IC} 0_{24 \mathrm{~h}}$. For the EB/AO staining, cells were resuspended in a $1: 1 \mathrm{~EB}(5 \mu \mathrm{g} / \mathrm{ml})$ and $\mathrm{AO}(10$ $\mu \mathrm{g} / \mathrm{ml}$ ) solution and morphological characteristics were observed in a fluorescence microscope (Olympus BX-FLA) using a 40x objective. For the Annexin assay, cells were incubated with $5 \mu \mathrm{L}$ of Annexin V-FITC according to the manufacturer's instructions and then acquired by flow cytometry as previously described.

\section{Evaluation of the mitochondrial membrane potential $(\Delta \Psi \mathbf{m})$}

K562 and Jurkat cells $\left(1 \times 10^{6}\right.$ cells/well $)$ were incubated for 12 hours with S1 at IC50 $24 \mathrm{~h}$. Cells were then incubated with a MitoView (Biotium ${ }^{\circledR}$, Fremont, USA) solution $(1: 10,000)$ for 30 minutes before flow cytometry acquisition (as previously described). The control groups (untreated cells) were considered as $100 \%$ of cells with an intact $\Delta \Psi \mathrm{m}$.

\section{Evaluation of apoptotic proteins by flow cytometry}

K562 and Jurkat cells $\left(1 \times 10^{6}\right.$ cells/well $)$ were incubated for 12 hours with S1 at IC50 $0_{24 h}$, except cells that would be labeled with anti- activated caspase-3, which were incubated for 24 hours. Cells were then permeabilized with BD Fix/Perm kit (BD Biosciences, New Jersey, USA) (except the cells used in FasR analysis) and labeled with the monoclonal antibodies conjugated to their respective fluorochromes, as follows: anti-BaxPerCP (Santa Cruz Biotechnology, Dallas, USA), anti-Bcl-2-FITC (EXBIO Praha a. s., Vestec, Czech Republic), anti-Survivin-PE (Santa Cruz 
Biotechnology, Dallas, USA), anti-AIF-FITC (Santa Cruz Biotechnology, Dallas, USA), antiactivated-caspase-3-V450 (BD Biosciences, New Jersey, USA) and anti-FasR-PE (EXBIO Praha a. s., Vestec, Czech Republic). Samples $(20,000$ events) were acquired at BD FACSCanto ${ }^{\mathrm{TM}}$ II as previously described and data were analyzed in Infinicyt software version 1.7. The medium fluorescence intensity (MFI) of the control groups (untreated cells) were considered as $100 \%$.

\section{Statistical analysis}

Results were expressed as mean \pm standard error of mean (SEM) and repeated at least twice, independently. A minimum significance level of $5 \%$ was adopted in relation to the control groups and the statistical analyzes were performed in GraphPad Prism 5 software. Student's $t$-test or analysis of variance (one-way or two-way ANOVA) complemented by the Bonferroni or Tukey post-hoc tests were used.

\section{RESULTS}

\section{Characterization of Sulfonamide S1}

Sulfonamide S1 described in this work is a compound unpublished in the literature. Using the general procedure previously described, S1 was obtained as an amorphous yellowish solid with a yield of 92\%. Mp.: 208.0-208.8 ${ }^{\circ} \mathrm{C} ;{ }^{1} \mathrm{H}$ NMR (400 $\mathrm{MHz}$, acetone- $\left.d_{6}\right) \delta: 8.79(\mathrm{~d} ; 2 \mathrm{H} ; J=2.2 \mathrm{~Hz} ; \mathrm{CH})$; $8.69(\mathrm{dd} ; 2 \mathrm{H} ; J=8.5$ e $2.2 \mathrm{~Hz} ; \mathrm{CH}) ; 8.40(\mathrm{~d} ; 2 \mathrm{H} ; J$ $=8.5 \mathrm{~Hz} ; \mathrm{CH}) ; 7.26(\mathrm{~s}, 2 \mathrm{H}, \mathrm{NH}) ; 3.41(\mathrm{~m}, 4 \mathrm{H}$, $\left.\mathrm{CH}_{2}\right) .{ }^{13} \mathrm{C}$ NMR (100 MHz, acetone- $\left.d_{6}\right) \delta: 151.23$; $149.13 ; 139.37 ; 133.26 ; 128.27 ; 121.43 ; 44.30$; HRMS (m/z) $521.0023[\mathrm{M}+\mathrm{H}]^{+}$, calcd 521.0027 for $\mathrm{C}_{14} \mathrm{H}_{12} \mathrm{~N}_{6} \mathrm{O}_{12} \mathrm{~S}_{2}$. These results can be seen in the supplementary material (Figures 2-4). After synthesis and characterization of $\mathrm{S} 1$, the tests were performed.

\section{In silico evaluation}

Sulfonamide S1 showed good characteristics for intestinal absorption and a positive result regarding the oral bioavailability, although it represented a low score (0.5571). The in silico prediction also suggests that S1 might be an inhibitor of CYP3A4 and CYP2C19 enzymes. On the other hand, the compound showed no potential as a substrate or inhibitor of P-gp. Sulfonamide S1 did not present potential for mutagenicity, tumorigenicity or irritating potential, and was classified as category III for acute oral toxicity $(500 \mathrm{mg} \mathrm{kg}-1<$ LD50 $\leq$ $5000 \mathrm{mg} \mathrm{kg} \mathrm{-1).} \mathrm{These} \mathrm{results} \mathrm{can} \mathrm{be} \mathrm{seen} \mathrm{in} \mathrm{the}$ supplementary Table 1.

\section{New sulfonamide $\mathrm{S} 1$ is strongly cytotoxic against AML and ALL cell lines}

Sulfonamide S1 reduced the viability of two AL cell lines, K562 and Jurkat, in a concentration and time-dependent manner (Figure 2A and B). After 12 hours, S1 was significantly more cytotoxic to ALL Jurkat (IC50: $6.0 \pm 0.4 \mu \mathrm{M}$ ) than to AML K562 (IC50: $10.7 \pm 0.6 \mu \mathrm{M}$ ). However, after 24 and 48 hours, the compound was similarly cytotoxic to both cell lines: IC50 $0_{\mathrm{K} 562}: 4.4 \pm 0.7 \mu \mathrm{M}$ and $3.0 \pm 0.4 \mu \mathrm{M}$ and IC50 Jurkat: $4.3 \pm 0.5 \mu \mathrm{M}$ and $1.1 \pm 1.8 \mu \mathrm{M}$ for 24 and 48 hours, respectively.

\section{Sulfonamide S1 is non-cytotoxic to non-tumor cells}

The IC50 obtained after 24 hours incubation of PBMC with $\mathrm{S} 1$ was $37.5 \pm 2.7 \mu \mathrm{M}$ (Figure 2C), which is more than eight times higher than the IC50 found in AL cells incubated with the compound for the same period. The SI was 8.5 when PBMC were compared with K562 and 8.7 when compared with Jurkat. In addition, sulfonamide S1 did not induce significant hemolysis in healthy erythrocytes even at a concentration much higher than the IC50 values found in AL cells $(100 \mu \mathrm{M})$ (Figure 2D). The hemolytic percentages ranged from $0,04 \pm$ $0,14 \%$ at $5 \mu \mathrm{M}$ to $0,83 \pm 0,5 \%$ at $100 \mu \mathrm{M}$.

\section{Sulfonamide $\mathrm{S} 1$ induces cell cycle arrest in $\mathrm{AL}$ cells}

Sulfonamide S1 significantly increased the proportion of cells at the Sub-G0/G1 phase (dead cells) in both AL cell lines when compared with the control group (untreated cells): a 3.7- and 6.8-times increase was observed in K562 and Jurkat dead cells after $\mathrm{S} 1$ treatment, respectively (Figure $3 \mathrm{~A}$

Table 1. Effect of sulfonamide S1 on the cell cycle of AL cell lines

\begin{tabular}{lllll}
\hline & K562 & & Jurkat & \\
\hline & Control & S1 & Control & S1 \\
\hline Sub G0/G1 (\%) & $4,68 \pm 0,68$ & $17,32 \pm 0,24$ & $5,05 \pm 1,84$ & $34,38 \pm 2,88$ \\
G0/G1 (\%) & $53,66 \pm 1,58$ & $44,09 \pm 2,94$ & $49,34 \pm 0,10$ & $74,50 \pm 6,398$ \\
S (\%) & $23,46 \pm 1,87$ & $23,22 \pm 1,69$ & $21,40 \pm 0,44$ & $18,63 \pm 4,61$ \\
G2/M (\%) & $22,79 \pm 1,27$ & $32,59 \pm 1,97$ & $29,27 \pm 0,53$ & $6,58 \pm 1,48$ \\
\hline
\end{tabular}



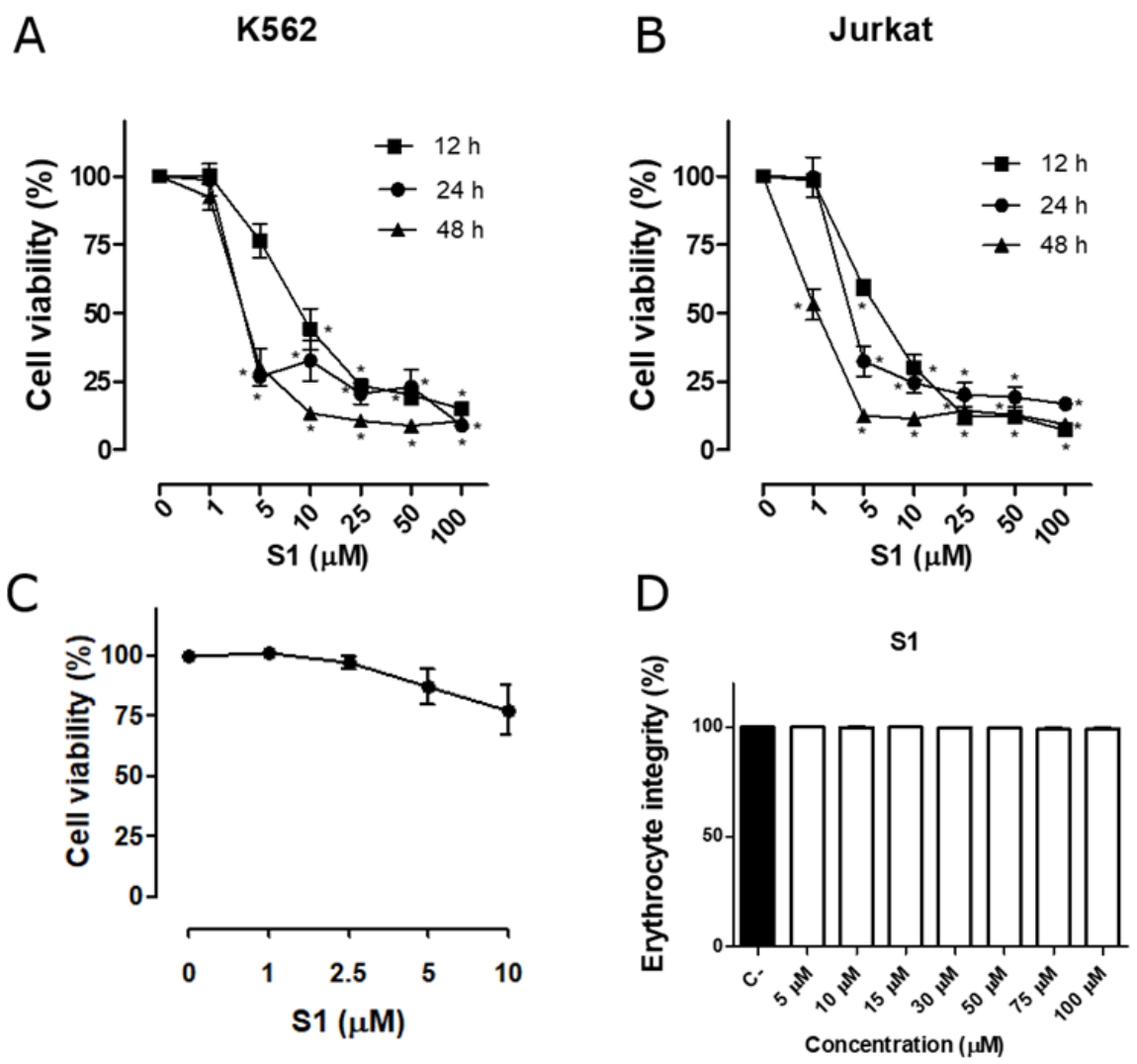

Figure 2. Cytotoxicity of sulfonamide S1 in K562, Jurkat, PBMC and erythrocytes. Cytotoxic effect of S1 in K562 (A), Jurkat (B), PBMC (C) and erythrocytes (D). The results are the mean \pm SEM of at least two independent experiments. *p $<0.05$ when compared to the control groups, using ANOVA followed by the Bonferroni post-hoc.

and $\mathrm{B}$, Table 1). The compound also blocked the G2/M phase in K562 cells, whereas in Jurkat cells, the blockage was observed at G0/G1 phase, as reflected by a significant increase in the percentage of cells at these phases when compared with the respective controls.

\section{Sulfonamide S1 induces apoptotic-like cell death in AL cells}

To assess whether the cell cycle arrest induced by sulfonamide S1 on AL cells led to apoptosis, the compound's effect on K562 and Jurkat cells morphology was first evaluated. Figure $3 \mathrm{C}$ and D shows that the control groups (untreated cells) presented uniform morphology with homogeneous cell size, intact membranes, and green fluorescence by AO. Oppositely, cells treated with S1 (Figure 3E and F) presented morphological changes mostly characteristic of late apoptosis, such as formation of apoptotic bodies, chromatin condensation and loss of membrane integrity, which allows the orange staining by EB. Characteristics of early apoptosis may also be observed in cells with intact membranes, stained in green, with chromatin condensation and bleb formation. Some cells also had reduced size, which may be associated with apoptosis. Although no significant difference was observed in K562 (Figure 3G), apoptosis was confirmed by phosphatidylserine externalization in Jurkat cells, which showed a significant increase of Annexin- $\mathrm{V}$ positive cells by $12.2 \pm 1.7 \%$ after being exposed to $\mathrm{S} 1$ (Figure $3 \mathrm{H}$ ).

Cytotoxicity induced by sulfonamide S1 involves intrinsic and extrinsic apoptosis

As shown in Figure 4A and B, S1 significantly reduced the proportion of cells with an intact $\Delta \Psi \mathrm{m}$ in both AL cell lines, as reflected by a reduction of $16.3 \%$ in K562 and $88.0 \%$ in Jurkat. This suggests the involvement of mitochondria in the cytotoxicity induced by this sulfonamide. The compound did not modulate the expression of $\mathrm{Bcl}-2$ and $\mathrm{Bax}$ (Figure 4C-F), however it significantly increased the expression of pro-apoptotic protein AIF in 
K562 cells by $17.3 \pm 2.1 \%$ (Figure $4 \mathrm{G}$ ), whereas in Jurkat cells there was no difference in AIF

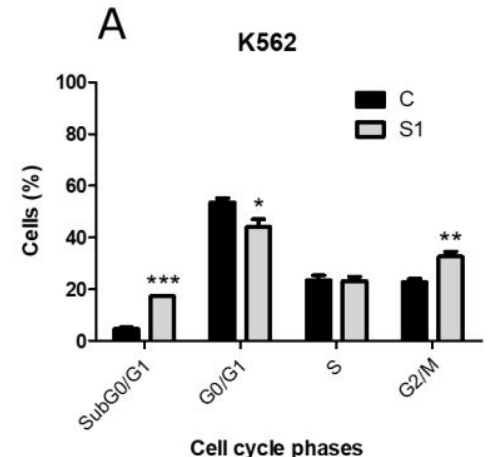

Control
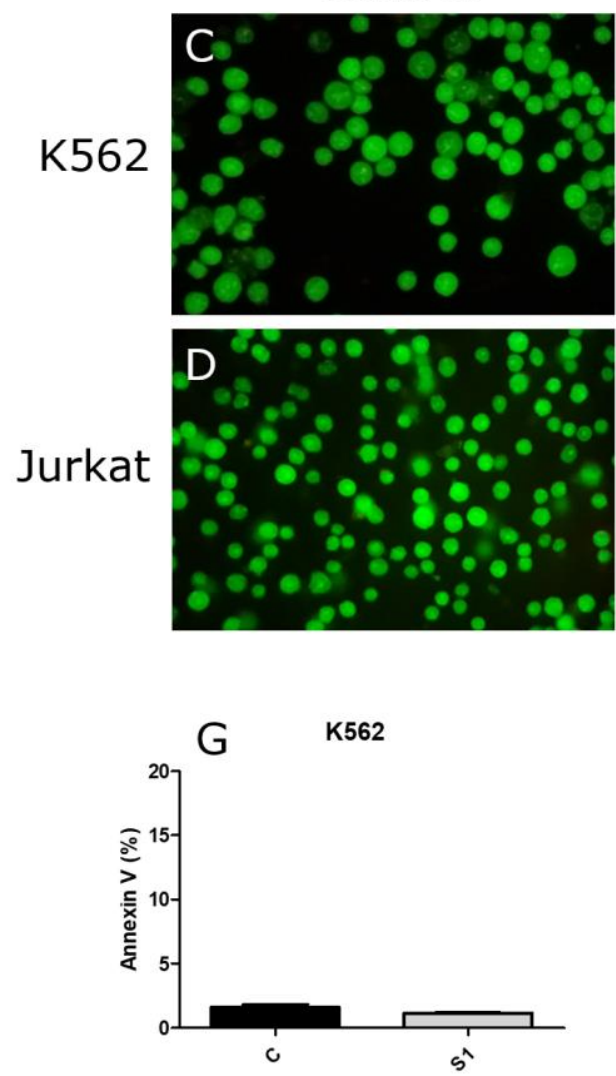

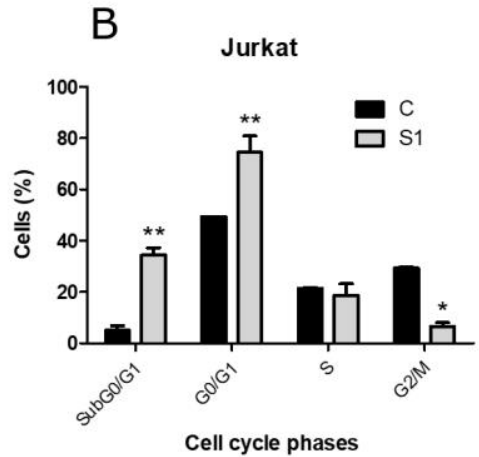

S1
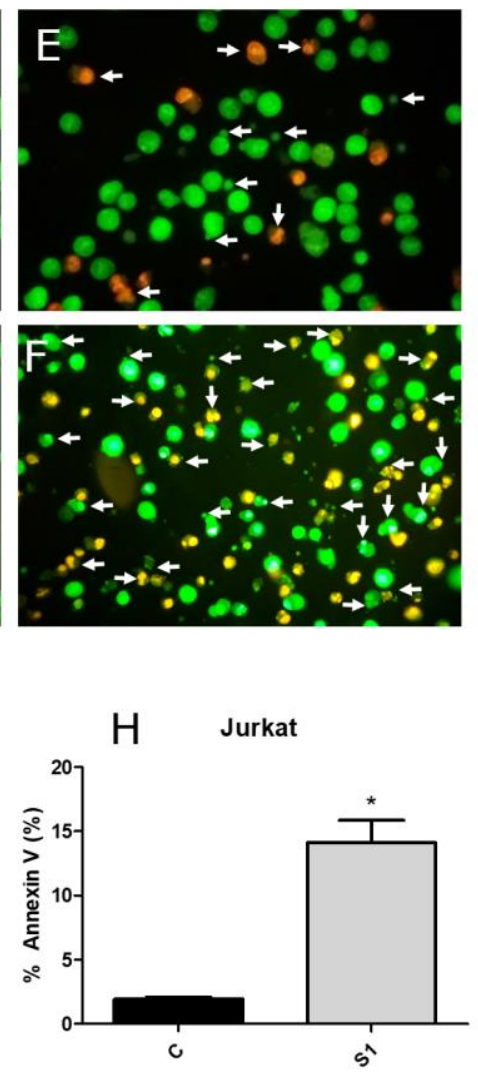

Figure 3. Effect of sulfonamide S1 on the cell cycle, cell morphology and phosphatidylserine (PS) exposure. K562 and Jurkat cells $\left(1 \times 10^{6}\right.$ cells/well) were incubated with S1 $\left(\mathrm{IC} \mathrm{C}_{24 \mathrm{~h}}\right)$ for 12 or 24 hours. The percentage of K562 (A) and Jurkat (B) cells in each cell cycle phase was determined by flow cytometry and were represented as G0/G1, S and G2/M. Cell morphology of treated and untreated K562 (C and E) and Jurkat (D and F) cells, respectively, were observed after staining with EB/AO and the white arrows show cells with apoptotic features. PS exposure was evaluated in K562 (G) and Jurkat $(\mathrm{H})$ cells after labeling with Annexin V-FITC. The control groups consisted of untreated cells. Results represent the mean \pm SEM of at least two independent experiments, one-way ANOVA followed by Tukey's post-hoc (cell cycle analyses) and Student's $t$-test (Annexin-V labeling analysis). *p $<0.05$, ** $\mathrm{p}<0.01$ and $* * * \mathrm{p}<0.001$.

expression (Figure 4H). In K562 cells, S1 also increased the expression of FasR by $18.0 \pm 5.5 \%$ (Figure 4I) (no difference in Jurkat cells - Figure $4 \mathrm{~J})$ and of activated caspase- 3 by $10.7 \pm 0.5 \%$ (Figure 4K) (no difference in Jurkat cells - Figure 4L). Although there was no difference in antiapoptotic protein Survivin expression in K562 (Figure 4M), in Jurkat cells, a significant decrease in Survivin was observed after treatment with S1 $(39.9 \pm 8.86 \%)($ Figure $4 \mathrm{~N})$. 

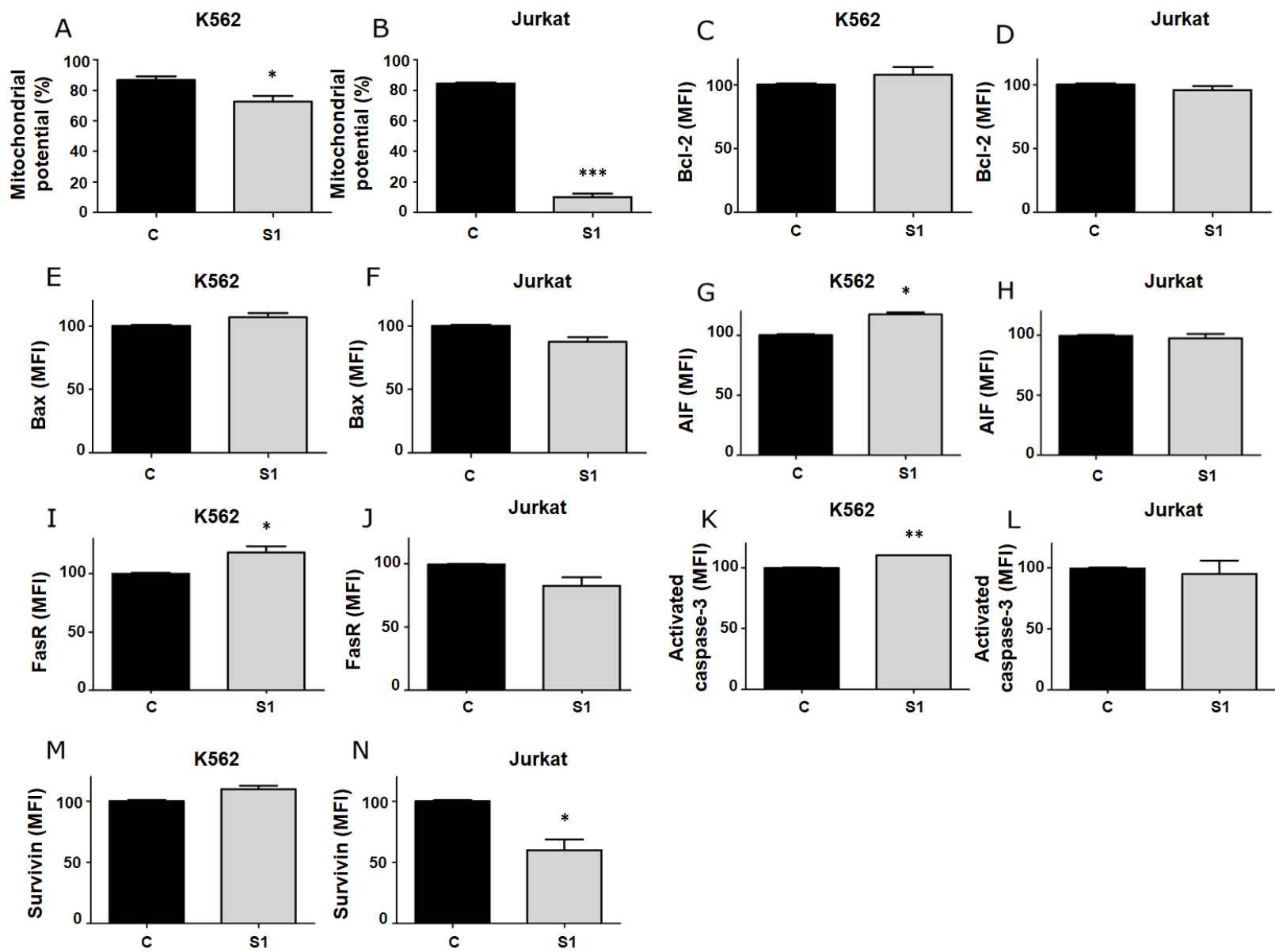

Figure 4. Effect of sulfonamide $\mathrm{S} 1$ in the mitochondria and in the expression of proteins involved in the apoptotic machinery. K562 and Jurkat cells (1 x 106 cells/ well) were incubated with S1 (IC5024h) for 12 or 24 hours. The $\Delta \Psi \mathrm{m}$ was assessed with the MitoView kit (A and B). Treated and untreated cells were labeled with anti-Bcl-2-FITC (C and D), anti-Bax-PerCP (E and F), anti-AIF-FITC (G and H), anti-FasR-PE (I and J), anti-activated-caspase-3-V450 (K and L) and anti-Survivin-PE $(\mathrm{M}$ and $\mathrm{N})$. Untreated cells were considered as control groups. The results represent the mean \pm SEM of at least two independent experiments, Student's t-test. $* \mathrm{p}<0.05$, ** $\mathrm{p}<0.01$ and $* * * \mathrm{p}<0.001$.

\section{DISCUSSION}

Malignant transformation of normal cells involves a series of events that occur gradually and culminates in the onset of cancer. Among these events are included the deregulation of cell division and proliferation, failures in DNA repair processes and disturbances in the process of regulated cell death (33). Cases of AL have grown worldwide in the past few years, while treatment for this disease is still mainly based on the same old non-selective cytotoxic drugs (6,33). Thus, non-tumor hematological cells such as lymphocytes, erythrocytes and granulocytes are also exposed to the cytotoxic activity of these chemotherapeutics, which leads to serious adverse effects, such as anemia, leukopenia, thrombocytopenia, and neutropenia (34). Therefore, considering the increased incidence of AL cases and the limitations of the currently available treatments, it is important to search for new and more efficient antileukemic compounds. For this reason, in this work we presented the cytotoxic and selective potential of a new synthetic sulfonamide, S1, in two AL cell lines, as well as the main mechanisms involved in cell death induced by this novel compound.

Initially, S1 was evaluated for its physicochemical properties and ADMET parameters. Although the compound had good intestinal absorption characteristics, oral bioavailability had a low score (0.5571), which indicates a low probability (just above 50\%). In 
addition, the compound violates the rules of Ghose (1999), Egan (2000), Lipinski (2000), Muegge (2001) and Veber (2002) for good oral bioavailability, due to its high molecular weight, TPSA and number of hydrogen bond donors and acceptors $(35,36,37,38,39)$. Nevertheless, this result does not discard the potential use of the compound in the future, since most drugs used in chemotherapy are administered by other routes. Furthermore, encapsulation or nanoencapsulation are good strategies that can be investigated. In silico prediction also evaluated the ability of the compound to interact with several proteins, such as Cytochrome P450 (CYP450) superfamily and glycoprotein-P enzymes. CYP450 superfamily enzymes plays a key role in drugs metabolism, and the inhibition or stimulation of these proteins can cause drug-drug interactions (40). Since the in silico prediction demonstrated that $\mathrm{S} 1$ might be an inhibitor of CYP3A4 and CYP2C19 enzymes, care should be taken when drugs metabolized by these enzymes are administered in combination, such as imatinib and omeprazole $(41,42)$. Sulfonamide S1 also showed no potential as a substrate or inhibitor of P-gp, which is an important result since P-gp is highly related to resistance to several drugs (43). Regarding the toxicity of the compound, sulfonamide S1 did not present potential for mutagenicity, tumorigenicity or irritating potential. The compound was classified as category III for acute oral toxicity, which suggests that it is nontoxic (44).

Next, we demonstrated that S1 was cytotoxic to both AML and ALL cell lines. In general, the IC50 values presented to K562 cells were slightly higher than those of Jurkat. According to the literature, K562 cell line is originated from an AML secondary to a chronic myeloid leukemia and it is positive for the BCR$\mathrm{ABL}$ fusion gene, which is associated with a worse prognosis as it can lead to an increased cell proliferation, blockade in cell differentiation and resistance to cell death induced by treatment $(45,46)$. On the other hand, Jurkat cell line is originated from a T-ALL in its first relapse (47). The differences between these AL subtypes and the aggressiveness of the BCR-ABL gene might explain why K562 lineage may be considered more resistant. In fact, several studies that evaluated the cytotoxicity of new compounds in these two cell lines have demonstrated that there is a tendency to obtain higher IC50 values in K562 than in Jurkat $(48,49)$. Different IC50 thresholds have been reported in the literature to determine whether a compound has a cytotoxic activity to the evaluated cell line. However, usually, it is established that compounds with high pharmacological impact have IC50 values below $10 \mu \mathrm{M}$ in vitro $(50,51)$. Sulfonamide S1 showed IC50 values below $10 \mu \mathrm{M}$ in both AL cell lines, which confirms its strong cytotoxic potential. This cytotoxic activity may be explained by the presence of four nitro $\left(\mathrm{NO}_{2}\right)$ groups in $\mathrm{S} 1$ structure (Figure 1). Nitro groups can be bioreduced and produce reactive oxygen species capable of damaging cells by oxidative stress $(52,53)$. Sulfonamide $\mathrm{S} 1$ also has two sulfonamidic groups, each one bounded to a benzene ring and, according to the literature, this group can interact with several pharmacological targets, such as DNA and amino acids (54). Thus, the presence of nitro groups as well as the presence of two sulfonamidic groups in S1 may contribute to its strong cytotoxic activity.

Other studies in the literature investigating sulfonamide derivatives in AL cells reported similar IC50 results, however, these studies usually used lower amounts of cells and/or longer incubation periods $(20,21,51,55,56)$. As the lower the number of cells exposed and the longer the incubation period, the more efficiently the compound will induce cell death, the cytotoxic results obtained for S1 are very promising, even when compared with similar studies.

To investigate whether a potentially new cytotoxic compound could be safely administered intravenously, the in vitro hemolysis test and the evaluation of cytotoxicity in PBMC are commonly performed to obtain preliminary safety results. Interestingly, sulfonamide $\mathrm{S} 1$ did not reduce the viability of PBMC even when incubated with twice the IC50 $24 \mathrm{~h}$ obtained in the AL cell lines, which suggests a possible selective activity against malignant cells. In fact, the SI between AL cells and PBMC were much higher than three, which according to the literature, is considered as a high selectivity $(29,30)$. Moreover, sulfonamide $\mathrm{S} 1$ was not cytotoxic to healthy red blood cells, as it did not induce the rupture of the erythrocyte membrane even at much higher concentrations compared to the IC50 found in AL cells. Since many of the chemotherapeutic agents currently used in AL treatments are administered intravenously and most of them are not selective for malignant cells, these tests are extremely important. Our results suggest that $\mathrm{S} 1$ has biocompatibility with the evaluated healthy cells (erythrocytes and PBMC), which might be associated with a lower range of adverse effects.

The results presented in this study showed that sulfonamide $\mathrm{S} 1$ led to cell cycle arrest at the G2/M and G0/G1 phases in K562 and Jurkat cell lines, respectively. Most studies investigating the 
effect of sulfonamides on hematological neoplastic cells do not provide much information regarding their cytotoxic mechanisms. However, our results corroborate the data presented in the literature reporting the inhibition of cell cycle progression with $\mathrm{G} 0 / \mathrm{G} 1$ or $\mathrm{G} 2 / \mathrm{M}$ blockade after treating different hematological malignancies cell lines with different sulfonamides or derivatives $(51,57,58)$. It is known that cell cycle arrest at the G2/M phase is mainly associated with disturbances in the microtubule's assembly (59), whereas arrest at G0/G1 affects the pre-synthesis of DNA (60). These results open the perspectives for more pathways that could be investigated in the future regarding S1 activity.

In general, when cellular damage, such as DNA damage, cannot be repaired during the cell cycle, intracellular events are stimulated and lead to regulated cell death such as apoptosis $(7,61)$. Our results demonstrated that sulfonamide $\mathrm{S} 1$ induces characteristic morphological alterations of early and late apoptosis in both $\mathrm{AL}$ cell lines. Furthermore, it is well established that the externalization of PS residues in the cell membrane is one of the first apoptotic signals (7). During apoptosis, PS is translocated from the inner to the outer membrane and, once exposed, Annexin-V can bind to these residues $(62,63)$. The significant increase in Annexin- $\mathrm{V}$ positive Jurkat cells, as well as the significantly increased expression of activated caspase-3 in K562, suggest that S1 induces an apoptotic-like cell death in AL cells.

Apoptosis is probably the most investigated type of cell death and is known to be involved in several biological processes, such as cell differentiation, normal cell turnover and removal of damaged cells (64). Thus, apoptotic mechanisms are fundamental for the maintenance of tissue homeostasis, while the dysfunction or the inhibition of apoptosis may be responsible for tumorigenesis $(65,66,67)$. Current therapies against various malignancies include drugs that target the apoptotic pathways, as the restoration of signaling involved in apoptosis activation is a promising target for the development of new antileukemic agents (64). In this regard, there are several proteins and organelles responsible for the activation, regulation, and execution of events necessary to lead to apoptotic cell death $(65,66,67)$. Damage to the mitochondria can cause $\Delta \Psi \mathrm{m}$ dissipation and, consequently, increase the mitochondrial membrane permeability and release pro-apoptotic molecules (68). After finding a significant $\Delta \Psi \mathrm{m}$ reduction in both $\mathrm{K} 562$ and Jurkat cells after S1 treatment, we evaluated the expression of some proteins involved in the activation of intrinsic apoptosis.

During intrinsic apoptosis, proteins from the Bcl-2 family, such as pro-apoptotic protein Bax and anti-apoptotic protein Bcl-2, control the formation of pores in the mitochondrial membrane, which affects the $\Delta \Psi \mathrm{m}$. Consequently, the modulation of these proteins may lead to the blockade or release of proteins involved in the activation of apoptosis $(67,69,70,71,72)$. Sulfonamide S1 did not alter the expression of Bax and Bcl-2, which suggests that these proteins are not involved in the cell death induced by this compound at the incubation period evaluated in this study. However, it is known that tumor cells acquire resistance to apoptosis by various mechanisms, which include the expression of antiapoptotic proteins or the down-regulation or mutation of pro-apoptotic proteins (72), which might be the case of K562 and Jurkat cells incubated with S1. Moreover, there are many other Bcl-2 family proteins, such as Bcl-xL, Bak, PUMA, etc, that have not been evaluated in this study. As we have shown evidence that S1 activates intrinsic apoptosis, the modulation of other Bcl-2 family proteins by this compound is a valid hypothesis.

The dissipation of $\Delta \Psi \mathrm{m}$ after $\mathrm{S} 1$ treatment significantly increased the expression of the apoptosis inducing factor (AIF) in K562, but not in Jurkat. AIF is one of the many pro-apoptotic proteins released to the cytosol by the mitochondria after $\Delta \Psi \mathrm{m}$ loss and is responsible for chromatin condensation when translocated to the nucleus, thus initiating apoptotic cell death independently of caspase activation $(73,74)$. Our results suggest that, in Jurkat cells, other mitochondrial pro-apoptotic proteins may be involved in cell death induced by $\mathrm{S} 1$, such as cytochrome c, endonuclease $\mathrm{G}$ and SMAC/Diablo. Furthermore, this cell line had a significant reduced Survivin expression after S1 treatment, which contributes to the apoptogenic signal. Survivin is the smallest protein of the inhibitors of apoptosis proteins (IAP) family and is involved in both apoptosis inhibition and cell cycle regulation. Survivin is expressed in all types of tumors and is correlated with tumor aggressiveness, resistance to chemotherapy and inhibition of caspase activation. Also, it is known that Survivin superexpression is associated with the inhibition of both intrinsic and extrinsic apoptosis $(7,75)$.

Differently from intrinsic apoptosis, the extrinsic apoptosis is initiated by the activation of proteins from the death receptor family that can translate signals from the extracellular space or 
neighboring cells to signaling components present in both cell membrane and cytoplasm. Among these death receptors is Fas (FasR), whose activation by its respective ligand (FasL) generates a series of events, such as caspase-8 activation and, consequently, caspase-3 activation (7). The significant increased FasR expression in K562 cells suggests that the activation of extrinsic apoptosis is another cytotoxic mechanism of compound S1 in AML cells. However, extrinsic apoptosis may not be excluded in Jurkat ALL cells as other membrane receptors might be activated by sulfonamide S1, such as TrailR.

Taken together, our results indicate that sulfonamide $\mathrm{S} 1$ is cytotoxic to AL cell lines and non-cytotoxic to non-tumor cells. Moreover, the compound acts by different mechanisms in AML and ALL, as PS exposure as well as the expression of proteins involved in intrinsic and extrinsic apoptosis were different in K562 and Jurkat cells treated with the compound. This is also evident in the cell cycle result, since S1 blocked different phases in AML and ALL cells. As ALs are heterogeneous diseases, different subtypes may respond differently to S1-induced cytotoxicity. Moreover, it is of interest to evaluate the expression of other proteins involved in intrinsic or extrinsic apoptosis, whose expression may or may not be altered after exposing the cells to this sulfonamide.

\section{CONCLUSIONS}

Sulfonamide S1 is a novel compound with potent in vitro biological activity against AL cells, with no significant toxicity to healthy cells, and has the potential to be further explored in the development of a new antileukemic drug. However, more studies are needed to elucidate the complete mechanisms of this compound in the induction of cell death.

\section{ACKNOWLEDGEMENTS}

The authors would like to gratefully acknowledge the contribution of Prof. Dr. Ana Carolina Rabello de Moraes, who helpfully revised the manuscript statistics. The authors thank the Chemistry Department of the Federal University of Santa Catarina and Central Laboratory of Structural Biology for providing the equipment and some of the facilities. We thank CNPq and CAPES (Brazil) for the scholarship grant and financial support.

\section{CONFLICT OF INTEREST}

The authors declare that they have no conflict of interest.

\section{REFERENCES}

1. Rose-Inman, H., and Kuehl, D. 2014. Acute Leukemia. Emerg. Med. Clin. North. Am. 32(3):579-596. DOI: https://doi.org/10.1016/j.emc.2014.04.004

2. Arber, D.A. et al. 2016. The Updated Who Classification Of Hematological Malignancies: The 2016 revision to the World Health Organization classification of myeloid neoplasms and acute leukemia. Blood, Washington. DOI: https://doi.org/10.1182/blood-2016-03643544.

3. Chung, C., and Ma, H. 2017. Driving Toward Precision Medicine for Acute Leukemias: Are We There Yet? Pharmacotherapy. 37(9):1052-1072. DOI: https://doi.org/10.1002/phar.1977.

4. Mwirigi, A. et al. 2017. Acute leukaemia. Medicine. $\quad$ 45(5):280-286. DOI:

https://doi.org/10.1016/j.mpmed.2017.02. $\underline{010 .}$

5. Rébé, C., and Ghiringhelli, F. 2015. Cytotoxic effects of chemotherapy on cancer and immune cells: how can it be modulated to generate novel therapeutic strategies? Fut, Oncol. 11(19): 2645-2654. DOI: https://doi.org/10.2217/fon.15.198.

6. Thomas, X., and Jeune, C.L. 2016. Current Management of Adult Acute Lymphoblastic Leukaemia: Emerging Insights and Outstanding Questions. EMJ Hematol. 4(1):117-128.

7. Galluzzi, L. et al. 2018. Molecular mechanisms of cell death: recommendations of the Nomenclature Committee on Cell Death 2018. Cell Death Differ. 25(3): 486-541. DOI: https://doi.org/10.1038/s41418-017-00124.

8. Papadantonakis, N., and Advani, A.S. 2016. Recent advances and novel treatment paradigms in acute lymphocytic leukemia. Ther. Adv. Hematol. 7(5):252269.

DOI: https://doi.org/10.1177/204062071665228 9. 
9. Saultz, J.N., and Garzon, R. 2016. Acute Myeloid Leukemia: A Concise Review. J. Clin. Med. 3(5):117-128. DOI: https://doi.org/10.3390/jcm5030033.

10. Bhati, S. 2017. In Silico Evaluation of Inhibitory Potential of Sulfonamide Derivatives against Diadenosine Tetraphosphate Hydrolase as Antimalarial Agents. Asian J. Pharm. Sci. 11(1):47-52. DOI:

http://dx.doi.org/10.22377/ajp.v11i01.108 7 .

11. Debbabi, K.F. et al. 2016. Synthesis and molecular docking against dihydrofolate reductase of novel pyridin- $\mathrm{N}$-ethyl- $\mathrm{N}$ methylbenzenesulfonamides as efficient anticancer and antimicrobial agents. J. Mol. Struct. 1131: 124-135. DOI: https://doi.org/10.1016/j.molstruc.2016.11 .048 .

12. Alaoui, S. et al. 2017. Synthesis and anticancer activities of new sulfonamides 4substituted-triazolyl nucleosides. Bioorg. Med. Chem. Lett. 27(9):1989-1992. DOI: https://doi.org/10.1016/j.bmcl.2017.03.01 8.

13. Maren, T.H. 1976. Relations Between Structure and Biological Activity of Sulfonamides. Annu. Rev. Pharmacol. Toxicol. 16(1): 309-327. DOI: https://doi.org/10.1146/annurev.pa.16.040 176.001521.

14. Mirian, M. et al. 2011. Synthesis and Cytotoxic Evaluation of Some Novel Sulfonamide Derivatives Against a Few Human Cancer Cells. Iran. J. Pharm. Res. 10(4): 741-748.

15. Wainwright, M., and Kristiansen, J.E. 2011. On the 75th anniversary of Prontosil. Dyes Pigm. 88(3): 231-234. DOI:

https://doi.org/10.1016/j.dyepig.2010.08.0 12.

16. Kołaczek, A. et al. 2014. Biological activity and synthesis of sulfonamide derivatives: a brief review. Chemik. 68(7): 620-628.

17. Tačić, A. et al. 2017. Antimicrobial sulfonamide drugs. Advanced Technologies. 6(1): 58-71.

18. Madácsi, R. et al. 2013. Aromatic Sulfonamides Containing a Condensed Piperidine Moiety as Potential Oxidative Stress-Inducing Anticancer Agents. Med. Chem. 9(7): 911-919. DOI: https://doi.org/10.2174/157340641130907 $\underline{0004}$.

19. Marzano, I. et al. 2013. Crystal Structure, Antibacterial and Cytotoxic Activities of a New Complex of Bismuth(III) with Sulfapyridine. Molecules. 18(2): 1464$1476 . \quad$ DOI: https://doi.org/10.3390/molecules 1802146 4.

20. Pingaew, R. et al. 2015. Novel 1,4naphthoquinone-based sulfonamides: Synthesis, QSAR, anticancer and antimalarial studies. Eur. J. Med. Chem. 103: 446-459. DOI: https://doi.org/10.1016/j.ejmech.2015.09. 001.

21. Oksuzoglu, E. et al. 2016. Antitumor activities on HL-60 human leukemia cell line, molecular docking, and quantumchemical calculations of some sulfonamide-benzoxazoles. Artif. Cells Nanomed. Biotechnol. 45(7): 1388-1396. DOI:

https://doi.org/10.1080/21691401.2016.12 41796.

22. Oliveira, A.S. et. al. 2016. New Sulfonamides Derived from Carvacrol: Compounds with High Antibacterial Activity against Resistant Staphylococcus aureus Strains. Journal of Biosciences and Medicines. $\quad \mathbf{4}: 105-114 . \quad$ DOI: https://doi.org/10.4236/jbm.2016.47011.

23. Buist, H. et al. 2013. The OSIRIS Weight of Evidence approach: ITS mutagenicity and ITS carcinogenicity. Regul Toxicol Pharmacol. 67(2):170-81.

24. Yang, H. et al. 2019. admetSAR 2.0: webservice for prediction and optimization of chemical

ADMET properties. Bioinformatics. 35(6): 1067 1069. doi:10.1093/bioinformatics/bty 707

25. Tennant, J.R. 1964. Evaluation of the trypan blue technique for determination of cell viability. Transplantation. 2: 685-694. DOI: https://doi.org/10.1097/00007890196411000-00001.

26. Mosmann, T. 1983. Rapid colorimetric assay for cellular growth and survival: application to proliferation and cytotoxicity assays. J. Immunol. Methods. 65(1-2): 55-63. DOI: https://doi.org/10.1016/00221759(83)90303-4.

27. Machana, S. et al. 2011. Cytotoxic and apoptotic effects of six herbal plants against the human hepatocarcinoma 
(HepG2) cell line. Chin. Med. 6(1): 39-47. DOI: https://doi.org/10.1186/1749-85466-39.

28. Peña-Morán, O. et al. 2016. Cytotoxicity, Post-Treatment Recovery, and Selectivity Analysis of Naturally Occurring Podophyllotoxins from Bursera fagaroides var. fagaroides on Breast Cancer Cell Lines. Molecules. 21(8): 1013-1028. DOI: https://doi.org/10.3390/molecules2108101 3.

29. Prayong, P. et al. 2008. Cytotoxic activity screening of some indigenous Thai plants. Fitoterapia. 79(7-8): 598-601. DOI: https://doi.org/10.1016/j.fitote.2008.06.00 7.

30. Dahham, S. et al. 2015. The Anticancer, Antioxidant and Antimicrobial Properties of the Sesquiterpene $\beta$-Caryophyllene from the Essential Oil of Aquilaria crassna. Molecules. 20(7): 11808-11829. DOI:

https://doi.org/10.3390/molecules2007118 08 .

31. Roger, R. et al. 1996. BCR-ABL does not prevent apoptotic death induced by human natural killer or lymphokine-activated killer cells. Blood. 87(3): 1113-1122. DOI: https://doi.org/10.1182/blood.V87.3.1113. bloodjournal8731113.

32. Salazar, J.G.G., and Sánchez, P.J. 2014. El Cáncer. Universidad Autónoma de Nuevo León, Monterrey.

33. Davis, A. et al. 2014. Leukemia: An Overview for Primary Care. Am. Fam. Physician. 89(9): 731-738.

34. Andrade, V. et al. 2013. Qualidade de vida de pacientes com câncer hematológico em tratamento quimioterápico. Rev. Esc. Enferm. USP. 2(47): 355-361. DOI: https://doi.org/10.1590/S008062342013000200012.

35. Ghose, A.K. et al. 1999. A knowledgebased approach in designing combinatorial or medicinal chemistry libraries for drug discovery. 1. A qualitative and quantitative characterization of known drug databases. J Comb Chem. 1(1):55-68. doi:10.1021/cc9800071

36. Egan, W.J. et al. 2000. Prediction of drug absorption using multivariate statistics. J Med Chem. 43(21):3867-77. doi:10.1021/jm000292e

37. Lipinski, C.A. et al. 2001. Experimental and Computational Approaches to Estimate Solubility and Permeability in
Drug Discovery and Development Settings. Adv Drug Delivery Rev. 46(13):3-26. doi: 10.1016/s0169409x(00)00129-0.

38. Muegge, I. et al. 2001. Simple selection criteria for drug-like chemical matter. J Med Chem. 44(12):1841-6. doi:10.1021/jm015507e

39. Veber, D.F. et al. 2002. Molecular Properties That Influence the Oral Bioavailability of Drug Candidates. J Med Chem. 45(12):2615-23. doi: 10.1021/jm020017n.

40. McDonnell, A.M. and Dang, C.H. 2013. Basic review of the cytochrome p450 system. J Adv Pract Oncol. 4(4):263-8.

41. Prograf (tacrolimus) package insert. AstellasPharma US. 2012 Retrieved from http://www.astellas.us/docs/prograf.pdf.

42. Gleevec (imatinib mesylate) package insert. Novartis Pharmaceuticals. 2012 Retrieved from http://www.pharma.us.novartis.com/produ ct/pi/pdf/gleevec_tabs.pdf.

43. Callaghan, R. et al. 2014. Inhibition of the multidrug resistance P-glycoprotein: time for a change of strategy? Drug Metab Dispos. 42(4):623-31.

44. Li, X. et al. 2014. In silico prediction of chemical acute oral toxicity using multiclassification methods. J Chem Inf Model. 54(4):1061-9.

45. Lozzio, C.B., and Lozzio, B.B. 1975. Human Chronic Myelogenous Leukemia Cell-Line With Positive Philadelphia Chromosome. Blood. 45(3): 321-334.

46. Kang, Z.J. et al. 2016. The Philadelphia chromosome in leukemogenesis. Chin. J. Cancer. 35 : 48.4 DOI: https://doi.org/10.1186/s40880-016-01080 .

47. Schneider, U. et al. 1977. Characterization of EBV-genome negative "null" and "T" cell lines derived from children with acute lymphoblastic leukemia and leukemic transformed non-Hodgkin lymphoma. Int. J. Cancer. 19(5): 621-626. DOI: https://doi.org/10.1002/ijc.2910190505.

48. Bubniak, L.S. et al. 2017. Effects of 1,3,5triphenyl-4,5-dihydro-1H-pyrazole derivatives on cell-cycle and apoptosis in human acute leukemia cell lines. Can. J. Physiol. Pharmacol. 95(5):548-563. DOI: https://doi.org/10.1139/cjpp-2016-0222.

49. Maioral, M.F. et al. 2017. Cytotoxic effect of a novel naphthylchalcone against 
multiple cancer cells focusing on hematologic malignancies. Biochimie. 140: 48-57. DOI: https://doi.org/10.1016/j.biochi.2017.06.0 04.

50. Hughes, J.P. et al. 2011. Principles of early drug discovery. Br. J. Pharmacol. 162(6): 1239-1249.

DOI:

https://doi.org/10.1111/j.1476-

5381.2010.01127.x.

51. Kamal, A. et al. 2011. Synthesis and apoptosis inducing ability of new anilino substituted pyrimidine sulfonamides as potential anticancer agents. Eur. J. Med. Chem. 46(12): 5817-5824. DOI: https://doi.org/1016/j.ejmech.2011.09.039

52. Soares, G.A. et al. 2009. Synthesis and in Vitro Cytotoxic Activity of Compounds with Pro-Apoptotic Potential. Molecules. 15(1): 12-26. DOI : https://doi.org/10.3390/molecules 1501001 2.

53. Lopes, M. et al. 2015. Synthesis of Nitroaromatic Compounds as Potential Anticancer Agents. Anticancer Agents Med. Chem. 15(2): 206-216. DOI: https://doi.org/10.2174/187152061466614 1114201749.

54. Supuran, C.T. 2017. Special Issue: Sulfonamides. Molecules. 22(10): 16421647.

DOI: https://doi.org/10.3390/molecules2210164 2.

55. Doungsoongnuen, S. et al. 2011. Investigation on biological activities of anthranilic acid sulfonamide analogs. Excli. Journal. 10: 155-161.

56. Reddy, M.V. et al. 2013. Design, Synthesis, and Biological Evaluation of (E)-N-Aryl-2-arylethenesulfonamide

Analogues as Potent and Orally Bioavailable Microtubule-Targeted Anticancer Agents. J. Med. Chem. 56(13): 5562-5586.

DOI: https://doi.org/10.1021/jm400575x.

57. Yoshimatsu, K. et al. 1997. Mechanism of action of E7010, an orally active sulfonamide antitumor agent: inhibition of mitosis by binding to the colchicine site of tubulin. Cancer Res. 57(15): 3208-3213.

58. Ling, T. et al. 2018. Novel vitexin-inspired scaffold against leukemia. Eur. J. Med. Chem. 146: 501-510. DOI: https://doi.org/10.1016/j.ejmech.2018.01. 004.
59. Raja, V. et al. 2014. Novel antitumour indole alkaloid, Jerantinine A, evokes potent G2/M cell cycle arrest targeting microtubules. Invest. New Drugs. 32(5): 838-850.

DOI: https://doi.org/10.1007/s10637-014-01261.

60. Jingwen, B. et al. 2017. Cell cycle regulation and anticancer drug discovery. Cancer Biol. Med. 14(4): 348362 .

DOI:

https://doi.org/10.20892/j.issn.20953941.2017.0033.

61. Visconti, R. et al. 2016. Cell cycle checkpoint in cancer: a therapeutically targetable double-edged sword. J. Exp. Clin. Cancer Res. 35(1): 153-161. DOI: https://doi.org/10.1186/s13046-016-0433$\underline{9}$.

62. Vance, J.E., and Tasseva, G. 2013. Formation and function of phosphatidylserine and phosphatidylethanolamine in mammalian cells. Biochim. Biophys. Acta. 1831(3): 543-554.

DOI: https://doi.org/10.1016/j.bbalip.2012.08.0 16.

63. Telford, W. et al. 2016. Measurement and Characterization of Apoptosis by Flow Cytometry. Curr. Protoc. Cytom. 77: 9.491-9.49.28.

DOI: https://doi.org/10.1002/cpcy.1.

64. Mishra, A.P. et al. 2018. Programmed Cell Death, from a Cancer Perspective: An Overview. Mol. Diagn. Ther. 22(3): 281295. DOI: https://doi.org/10.1007/s40291018-0329-9.

65. Papaliagkas, V. et al. 2007. The proteins and the mechanisms of apoptosis: A minireview of the fundamentals. Hippokratia. 11(3): 108-113.

66. Letai, A. 2017. Apoptosis and Cancer. Annu. Rev. Cancer Biol. 1(1): 275-294.

DOI:

https://doi.org/10.1146/annurevcancerbio-050216-121933.

67. Pfeffer, C.M., and Singh, A.T.K. 2018. Apoptosis: A Target for Anticancer Therapy. Int. J. Mol. Sci. 19(2): 448-458. DOI:

https://doi.org/10.3390/ijms 19020448.

68. Burke, P.J. 2017. Mitochondria, Bioenergetics and Apoptosis in Cancer. Trends Cancer. 3(12):857-870. DOI: https://doi.org/10.1016/j.trecan.2017. 
69. Gross, A. et al. 1999. BCL-2 family members and the mitochondria in apoptosis. Genes Dev. 13(15): 1899-1911.

70. Wong, R.S. 2011. Apoptosis in cancer: from pathogenesis to treatment. J. Exp. Clin. Cancer Res. 30: 87-101. DOI: https://doi.org/10.1186/1756-9966-30-87.

71. Cosentino, K., and García-Sáez, A.J. 2014. Mitochondrial alterations in apoptosis. Chem. Phys. Lipids. 181: 6275.

DOI: https://doi.org/10.1016/j.chemphyslip.201 4.04.001.

72. Hassan, M. et al. 2014. Apoptosis and Molecular Targeting Therapy in Cancer. Biomed Res. Int. 2014: 150845. DOI:

https://doi.org/10.1155/2014/150845.

73. Dyshlovoy, S.A. et al. 2017. Frondoside A induces AIF-associated caspaseindependent apoptosis in Burkitt lymphoma cells. Leuk. Lymphoma. 58(12): $\quad 2905$ 2915. DOI: https://doi.org/10.1080/10428 194.2017.1317091.

74. Bano, D., and Prehn, J.H.M. 2018. Apoptosis-Inducing Factor (AIF) in Physiology and Disease: The Tale of a Repented Natural Born Killer. Ebiomedicine. 30:29-37. DOI: https://doi.org/10.1016/j.ebiom.2018.03.0 16.

75. Garg, H. et al. 2016. Survivin: a unique target for tumor therapy. Cancer Cell Int. 16: 49. DOI: https://doi.org/10.1186/s12935-016-03261. 